\title{
Arbor
}

\section{Asociación Española de Terminología}

\section{Ángel Martín Municio}

Arbor CLXXIX, 706 (Octubre 2004), 541-547 pp.

La terminología puede tener, de un lado, una consideración objetiva independientemente de la lengua utilizada. Pero, puede contemplarse, además, desde el ángulo particular de una lengua dada, y ser de consideración, no por adicionales menos importantes, asuntos pertenecientes a los ámbitos de las políticas lingüística y técnica de una nación, del tipo de la armonización y la difusión de los recursos terminológicos, la coordinación de las acciones y las relaciones internacionales.

Del primer lado, la consideración objetiva de la terminología debe ir en busca de la selección de términos y vocabularios de áreas específicas del conocimiento, definirlos rigurosamente, estar al tanto de su evolución y de la génesis de nuevas ideas y nuevos términos en las lenguas de su creación. Objetivos que por sí solos construyen y relacionan la terminología con otros campos del conocimiento: la lexicografía, la traducción, la redacción técnica, la documentación, y, obviamente, los saberes propios del área de que se trate. Y sin que sea necesario, quizás tampoco posible, establecer límites definidos entre las áreas limítrofes, ya que, antes al contrario, será de su interacción conjunta de la que salgan beneficiados todos los sectores participantes. Relaciones e influencias que habrán de ser tenidas en cuenta en todo momento en que se plantee la naturaleza de la formación académica, la especialización interdisciplinar y el ejercicio cooperativo de los cultivadores de las diversas áreas.

A este propósito, no olvidemos que la lengua es la primera ciencia que posee el hombre. La lengua es una primera clasificación del mundo, y ella nos muestra una organización de la realidad; pero esta inicial descripción científica por el lenguaje natural sirve demasiado trabajosamente a cier- 


\section{Ángel Martín Municio}

tos tipos de realidades científicas. El desarrollo de la ciencia y la continua aparición de nuevos dominios van acompañados de una necesidad de superación del lenguaje natural. La lengua natural sirve, sin embargo, a manera de cañamazo sobre el que se enjaretan los términos específicos de la terminología científica, con pretensiones más o menos universalistas, e, incluso, los mismos sistemas simbólicos con ambición universalista plena. Es a modo de un nivel especial dentro de la lengua general; se trata de una lengua modificada, de un sistema de signos dotado de menos ambigüedad, que se usa juntamente con la lengua natural en proporciones variables. De otra manera, entre el lenguaje natural y el lenguaje lógico-matemático con mayor grado de simbolismo existe un gradiente de cientificismo que tiende hacia la abstracción y a un mejor ajuste a la estructura de la realidad. Todos los dominios de la ciencia se empeñan, sin embargo, en crear un lenguaje simbólico apropiado a su objeto. Objetividad y cuantificación que se van alejando de los modos usuales del lenguaje, a la vez que este se adapta en su intento de lograr aquellos fines.

La naturaleza compleja y extensa de los hechos de la ciencia, su amplitud y difusión, y la inmediatez de sus aplicaciones, obligan a erigir con rapidez y a introducir con pulcritud y precisión los vocablos científicos en la propia lengua. Términos que cada día logran con más prontitud el rango de usos de la cultura y alcanzan la comunicación popular de la ciencia. Y no deja de resultar coincidente que la máxima capacidad creadora en el terreno científico actual se corresponda con la fácil tolerancia de la lengua inglesa a la invención de palabras. La mezcla de raíces de diferentes orígenes o las composiciones lingüísticas irregulares, traducidas en la falta de escrúpulos semánticos o léxicos y en la ausencia de trabas académicas, han hecho de la lengua inglesa el contrapunto de la rígida elaboración de la lengua castellana, intolerante frente a reales o hipotéticas veleidades lingüísticas. Y con gran frecuencia se habla de tecnicismos con un deje de amargura y celos disfrazado de corrección y de purismo, queriendo ignorar que constituyen la inmensa mayoría de las innovaciones lingüísticas actuales. Con gran frecuencia también -aquí tengo un ejemplo de hace pocos días- se opina sin el menor conocimiento del significado, de la historia y del uso de los términos; lo que, ciertamente, no contribuye a las deseables relaciones de vecindad.

El Diccionario de Autoridades (1713-1740) recogió ya, en efecto, algunos tecnicismos. Sin embargo, ni la ciencia moderna había aún entrado en agujas, ni había nacido la preocupación social por la ciencia y sus efectos, ni tampoco la Academia podía tener la preparación y la homogenei- 
dad suficientes para hacer frente a semejante situación. Habrá que tener en cuenta que este diccionario se terminó medio siglo antes de que Lavoisier estableciera los principios de la nomenclatura química (1787) y docenas de años antes del enunciado de las grandes leyes de la química. Situación histórica que ha de tenerse presente para enjuiciar críticamente el contenido de la terminología científica del Diccionario de Autoridades y de las primeras ediciones del Diccionario de la Lengua Española. Situación que subraya nuevamente la necesidad de que las terminologías especializadas, y en particular la terminología científica, vayan acompañadas en todo momento del conocimiento del área de especialización y de su historia.

De entonces acá, la ciencia ha seguido su camino; y resulta casi una trivialidad insistir en que ningún otro periodo de la historia puede exhibir un paralelismo con el presente crecimiento exponencial de los resultados y los efectos del adelanto científico-tecnológico. Nuestro actual sistema del mundo está dirigido dominantemente por la tecnología. Las consecuencias de la revolución industrial, a finales del XVIII, cambiaron de modo fundamental la vida y la sociedad de los países industrializados y, de manera gradual, se asimilan por las partes menos desarrolladas del mundo. Además, la llamada sociedad de la información en la que estamos sumergidos está produciendo una transformación aún más profunda. Nos encontramos, efectivamente, en un periodo de profunda transición en el que habrán de tomarse decisiones vitales que actualicen las promesas de beneficio para toda la humanidad. Y a buen seguro que no hay que esforzarse demasiado para palpar la influencia de las ciencias y de la tecnología sobre el clima material e intelectual de nuestra época, incluidas las manifestaciones lingüísticas y de la comunicación. Relevancia que puede condensarse en la expresión de la ciencia como estilo de vida.

Así, el hombre adulto de hoy conoce que cuando nació acababa de comenzar la aplicación de la penicilina, no se había inventado el transistor y, en geología, no se hablaba de la tectónica de placas. Los elementos químicos rondaban el centenar frente a los 112 hoy reconocidos y nombrados, con los múltiples problemas que su bautismo ha originado. Nadie había oído hablar de los púlsares y los quásares. No existía ninguna de las técnicas hoy tan populares de la imagen médica, al estilo de la ecografía, la resonancia magnética, la tomografía computarizada o la angiografía. Más aún, en poco más de una década los métodos de la biotecnología han originado los anticuerpos monoclonales, los animales y vegetales transgénicos, la fertilización in vitro y la terapia génica. Los descubrimientos en el campo de los nuevos materiales han dado origen a 
los semiconductores, los carcerandos, los nanotúbulos y los fulerenos. De las ciencias de la computación y de la ingeniería del conocimiento han emergido con extraordinaria rapidez nuevos lenguajes de programación, las redes neuronales y la inteligencia artificial, que intentan desvelar o imitar, a toda la distancia que se quiera, el funcionamiento del cerebro humano. Muchos recientes conceptos científicos de la biología molecular responden a nuevas acepciones del lenguaje vulgar: expresión, recombinación, traducción, transcripción, transducción, receptor, canal, etc. con un significado absolutamente diferente. Y en nuestros mismos días nacen nuevos campos de la ciencia a los que hay que nombrar, al estilo de la proteinómica y la genómica como estudios respectivos de las proteínas y los genes, y sus respectivas modificaciones estructurales y funcionales.

Como consecuencia de todo ello, las publicaciones de los últimos años en los campos variados de la ciencia y de la técnica están dando origen a un nuevo lenguaje que contiene unos 3.000 términos técnicos adicionales innovados cada año; con muchísima diferencia, el mayor porcentaje de todas las innovaciones lingüísticas. Datos contundentes de la rapidez y la insistencia con que los avances de la ciencia y la tecnología se abren paso en la terminología de la ciencia. Y, así, quienes tabulan el crecimiento de las ciencias están simplemente trazando el nuevo mapa del mundo. Y en este mapa se puede contemplar que más del 95 por ciento de todos los hombres y mujeres de la ciencia de todos los tiempos están vivos en la actualidad; que el número de trabajos relevantes en los campos de la física, la química y la biología, durante los últimos años, pasa de los tres millones; y que en cada una de las últimas décadas se duplican los índices críticos de las publicaciones científicas.

La relevancia y los avances de la ciencia se influyen mutuamente, con el resultado cotidiano de nuevos hechos acerca del mundo y del hombre. Lo atestiguan los nuevos campos abiertos en la última década acerca de nuevas moléculas y nuevos materiales, la colección de nuevos compuestos de reconocimiento y comunicación entre las células, las nuevas partículas subatómicas, los numerosos productos e, incluso, los nuevos seres vivos creados por las originales herramientas de la biotecnología, etc.; cada uno de ellos, a fin de cuentas, subsistema del amplísimo campo semántico constituido por el macrosistema ciencia.

Resulta indudable que frente al progreso diario de la creación científica y de su comunicación internacional, el diseño terminológico está obligado a exhibir un dinamismo que se traduzca en responder con prontitud crítica a los nuevos estándares internacionales, por ejemplo de las unida- 
des de medida y sus símbolos, y de los cambios habituales de denominación en las nomenclaturas especializadas, como los que han tenido lugar recientemente en los elementos químicos de número atómico 106 a 112; en utilizar los elementos compositivos propios de la derivación léxica; en adecuarse a los cambios y complicaciones frecuentes de la sinonimia; en estar vigilante frente a los cambios sincrónicos de la terminología que se producen en los momentos de reestructuración de los dominios científicos, por ejemplo, en los cambios colesterina a colesterol, nucleínico a nucleico, proteínico a proteico, y en los cambios de acentuación que el uso de los especialistas -de los que lo usan- ha ido imponiendo, nucleótido hacia nucleotido, éster y ésteres hacia ester y esteres. Dinamismo que ha de extenderse a la solución de los problemas que ha ido presentando, por ejemplo, los mencionados cambios fonéticos que el empleo progresivo va estableciendo, la relación entre formas nominales y verbales, los problemas planteados por la aposición de sustantivos en los lemas compuestos y a la formación de plurales y en la adopción de criterios en el empleo de siglas, por ejemplo el de la universalización frente al particularismo. Es, en resumen, en el nacimiento de los nuevos vocablos, o mientras su asentamiento es oscilante, es decir a su tiempo, cuando el trabajo terminológico ha de ser más atento y cuidadoso.

Así pues, y habida cuenta de estas ideas, más o menos compartidas pero indiscutibles, la ASOCIACIÓN ESPAÑOLA DE TERMINOLOGÍA intenta conectar los intereses y los logros de la comunidad lingüística especializada con aquellos otros que sirven a la sociedad y a la cultura. De otra manera, los ingredientes básicos de la actividad científica de la terminología tienen que buscar un procedimiento para dar el debido cauce a la presentación de sí misma, a la comunicación del nuevo conocimiento como compromiso social y a la transformación del hecho profundo de la verdad científica en opinión del individuo, primero, como conocimiento superficial propio del vulgo, y , después, en opinión pública como atención colectiva y general. En particular, la terminología de la ciencia ha de servir a la comunicación interna de la ciencia y, a la vez, al conocimiento público de la ciencia y a la promoción de la cultura científica y tecnológica. De un lado, la comunicación interna posibilita el paso fácil a través de los dominios particulares de la ciencia. Paso entre las fronteras disciplinares que es el mismo que ocurrió en la creación científica cuando los hallazgos del químico Pasteur o el físico Röntgen revolucionaron la medicina; o cuando, actualmente, la biotecnología se beneficia de los vuelos espaciales al conseguir una mejor purificación de proteínas y enzimas en condiciones de ingravidez. Sirve además esta multiplicidad de dominios para 
que el especialista no pierda el contacto con los estándares establecidos por otros especialistas y para que todo su componente terminológico científico y técnico participe en numerosas cuestiones de política pública.

Por otro lado, si desde la revolución científica, hace tres siglos, la repercusión económica y social de la ciencia, y por tanto de su terminología, constituyen un soporte del Estado, a nadie puede extrañar la posición excepcional de la autonomía de la ciencia en el conjunto de la cultura universal. Además, tampoco hace falta excesiva clarividencia para darse cuenta de que la penetración del lenguaje de la ciencia y de la técnica no es sólo un problema lingüístico sino que ocupa un lugar importante en los planteamientos políticos y económicos. De esta manera, a la relevancia de la ciencia y a sus relaciones culturales y sociales se une el valor añadido de que su adquisición y su comunicación pertenecen a esa especie de soberanía compartida que es el idioma común. Soberanía compartida que exige la existencia de los inventarios de voces técnicas y la normalización terminológica de la ciencia en español. Y posiblemente, esta sociedad de la información en la que nos encontramos inmersos puede tanto favorecer la esperanza como el desespero; todo dependerá de cómo nosotros sepamos utilizar con este fin las modernas comunicaciones y el poder de la terminología.

Finalmente, si la terminología, como tratamiento objetivo de los términos y vocabularios de un área del conocimiento, debe cumplir los fines generales establecidos, válidos para cualquier lengua, la terminología de la ciencia en español tiene unas exigencias particulares motivadas por la necesaria intelectualización de la lengua, que sea capaz de expresar todas las ideas y realidades contemporáneas, en particular en las áreas científicas, técnicas, jurídicas y sociales -económicas fundamentalmente- y de participar y difundirse a través de las nuevas tecnologías de la información; por su participación imprescindible en los tratamientos automatizados del lenguaje; por el número total de sus hablantes y el de las naciones miembros de la comunidad lingüística; por la evolución demográfica de los hablantes y de las comunidades científicas; por la importancia de su presencia en el contexto internacional y científico en el que se desarrollan las actividades de terminología y de normalización, que ponen en juego partidas económicas nada despreciables; y por su consideración como herramienta política en las relaciones internacionales, sobre todo con los países hispanoamericanos.

Ante estas consideraciones globales cabe preguntarse si la organización de la neología y la terminología en las lenguas de España responden 
a tales exigencias. No quisiera entrar ahora a juzgar esta respuesta; si a asegurar que La ASOCIACIÓN ESPAÑOLA DE TERMINOLOGÍA nace para arrimar el hombro en la solución de estas exigencias, para suplir todo lo parcialmente que se quiera algunas de las imprescindibles acciones de coordinación.

De esta serie de ideas y de ejemplos queda bien claro, de un lado, la trascendencia de los hechos de la ciencia y de la técnica, y, de otro, que el sentido de adelantamiento tiene que ser una norma de la terminología y, particularmente, de la terminología de la ciencia. A ello se refería Marañón, ya en 1956, con motivo del II Congreso de Academias de la Lengua Española. Decía así: La vida no se divide ya en literaria y técnica. Quiérase o no, somos ya todos técnicos. El poeta más puro o el filósofo que vive en pura abstracción están necesariamente contaminados cada una de las horas del día con las ciencias y con su lenguaje, por la sencilla razón de que todos la necesitan. La ciencia y la técnica tienen la vitalidad y la razón de ser suprema de su necesidad y de que, inexorablemente, lo será más cada día. Y su lenguaje es igualmente inseparable de la vida y, en consecuencia, tiene derecho también al cuidado oficial, es decir, a la misma fijeza y al mismo esplendor de sus vocablos literarios. 